\title{
Imagens de anúncios publicitários e consumo: contribuições pedagógicas e ambientais.
}

\author{
Advertisements images and consumption: pedagogical and environmental considerations \\ Luciana Richter' ; Vanessa Freitag ${ }^{2}$ \\ 'Licenciada em Ciências Biológicas; Mestre em Educação/UFSM. Docente do Curso de Ciências Biológicas, Laboratório de Ensino, Centro \\ de Educação Superior Norte do RS - CESNORS, Universidade Federal de Santa Maria - UFSM, Campus de Palmeira das Missões. \\ ${ }^{2}$ Licenciada em Desenho e Plástica; Mestre em Educação/UFSM; Doutora em Ciências Sociais/CIESAS-Occidente. Professora da Universi- \\ dad de Guanajuato, Campus León, México.
}

\begin{abstract}
Resumo
O presente texto pretende discutir a estreita relação existente entre imagens de anúncios publicitários, a cultura consumista e o espaço educativo. Partimos de uma experiência com docentes da rede pública, onde se discutiu a relação entre imagens publicitárias e o consumo de produtos, e se refletiu sobre a importância de se abordar esta temática no contexto educativo, com foco na questão ambiental. Nesse sentido, as imagens publicitárias serviram de subsídios para pensar a prática pedagógica de docentes da rede pública de São Gabriel - RS. Os dados empíricos desse estudo foram produzidos através de parte de uma oficina realizada com 23 professores no mês de outubro de 2012.
\end{abstract}

Palavras Chave: Imagens publicitárias; cultura consumista; educação ambiental; educação com imagens;

\begin{abstract}
This paper discusses the relationship between advertisements images, consumer culture and educational environment. We start from an experience with teachers from public schools, where are discussed the relationship between publicity images and product consumption, and reflected the importance of addressing this issue in the educational context, with a focus on environmental issues. In this sense, the images served as advertising tools to reflect the pedagogical practice of teachers located in São Gabriel - RS. The empirical data of this study were produced through part of a workshop held with 23 teachers in October 2012.
\end{abstract}

Keywords: advertisements images; consumer culture; environmental education; education with images. 


\section{INTRODUÇÃO}

A civilização humana e sua relação com a cultura consumista, impulsionada nos últimos anos com o advento da tecnologia, têm levado o planeta a uma devastação de seus ecossistemas fundamentais e nos impele a pensar: até onde o consumo desenfreado pode nos conduzir?

Nesse sentido, torna-se relevante pensar sobre a estreita interface existente entre educação e publicidade, posto que em alguns momentos não podemos estabelecer quem ensina mais da e para a vida. O papel que a publicidade passou a ocupar em nossas vidas tornou-a uma importante pedagogia, ou melhor, um local pedagógico que além de nos oferecer seus produtos, também nos brinda com estilos de vida, padrões de comportamentos e beleza, refletindo e ditando as tendências que vão sendo construídas culturalmente.

De maneira geral, este artigo objetiva refletir criticamente sobre a relação existente entre anúncios publicitários e o consumismo, visando problematizar a influência dessas imagens na vida cotidiana e especialmente, no contexto educativo, na vida de professores e estudantes. A utilização de imagens publicitárias foi proposta a partir da comparação das mesmas com as imagens encontradas em livros didáticos utilizados no ensino fundamental e médio. Portanto, as imagens publicitárias serviram de subsídios para pensar a prática pedagógica de docentes da rede pública de São Gabriel - RS. Os dados empíricos desse estudo foram produzidos através de uma oficina realizada com 23 professores no mês de outubro de 2012.

As atividades foram uma importante estratégia para refletir sobre as imagens publicitárias. Conforme Kellner (2009), torna-se necessário desenvolver conexões que capacitem os indivíduos discernirem as compulsões e as atrações ocultas por trás de certas formas de comportamento do consumidor, capacitando-os a adquirirem um alfabetismo crítico em relação à publicidade, favorecendo competências emancipatórias que possibilitem aos indivíduos resistirem à manipulação por parte do capitalismo de consumo.

Diante desse processo de utilização de imagens, que visam capturar a atenção dos consumidores, procurando convencê-los e padronizando estilos de vida, a escola tem um vasto campo de problematização e interferência se assim o desejar. De acordo com Rocha (2000), a mídia costuma influenciar de modo incisivo a sociedade, produzindo e fazendo circular um grande número de informações, a exemplo das facilidades de comunicação entre indivíduos de diferentes partes do planeta e de forma simultânea, constituindo verdades e certezas, multiplicando, reforçando e inventando formas de viver e pensar o mundo. Sobre este ponto, Silverstone (2005) acrescenta:

É no mundo mundano que a mídia opera de maneira mais significativa. Ela filtra e molda realidades cotidianas, por meio de suas representações singulares e múltiplas, fornecendo critérios, referências para a condução da vida diária, para a produção e manutenção do senso comum (SILVERSTONE, 2005, p.20).

As representações expostas na mídia conseguem filtrar elementos de nosso cotidiano, sendo que somos influenciados à medida que aceitamos as suas proposições e também quando julgamos que determinada marca comercial, produto ou ideia, poderão nos tornar pessoas melhores, mais bonitas, mais aceitáveis, proporcionando-nos um diferencial. É esse diferencial que nos atrai, é o desejo de nos tornarmos singulares em relação à maior parte da população, é o desejo pelo suposto poder que acaba padronizando nossos outros desejos, estipulando critérios e referências que ditarão regras para condução de nossas vidas.

Para Silverstone (2005) passamos a depender da mídia impressa e eletrônica, para fins de entretenimento e informação, conforto e segurança. Do mesmo modo pensa Ghilardi (1999, p.105), quando afirma que a mídia "colabora para a construção da identidade cultural do povo; é portanto, meio de transmissão cultural, e, o mais importante, constrói a opinião pública". A opinião pública é então, uma construção cultural que se dá através da formação do senso comum:

A mídia depende do senso comum. Ela o reproduz, recorre a ele, mas também o explora e distorce. Com efeito, sua falta de singularidade fornece o material para as controvérsias e os assombros diários, quando somos forçados - em grande medida pela mídia e, cada vez mais, talvez apenas pela mídia - a ver, a encarar os sensos comuns dos outros. Além disso é pelo senso comum que nos tornamos aptos, se é que de fato nos tornamos, a partilhar nossas vidas uns com os outros e distingui-las umas das outras (SILVERSTONE, 2005, p.21). 
Os sensos comuns acabam por ser partilhados coletivamente através da mídia, à medida que as nossas diferenças e similaridades culturais passam a ser expostas e utilizadas como forma de chamar a nossa atenção, de levar nossas vidas para o centro do palco. Ao mesmo tempo, os sensos comuns também são produzidos por meio da mídia, e isso acontece quando nos identificarmos com o que é exposto ou exibido, podemos capturar essas informações e com elas construir sistemas de "verdades" compartilhadas.

Conforme Rocha (1999), mídia é um local privilegiado de informação e diversão e também um local privilegiado de educação, tendo sido principalmente nas últimas décadas, um ambiente pedagógico onde se ensina e aprende pela legitimação e construção de identidades.

Como afirma Lopes (2004, p.62): "grande parte do que sentimos, sabemos ou dizemos relaciona-se com o que recebemos das mídias". A presença da mídia em nosso cotidiano é inegável, e Silverstone (2005) reitera:

A mídia nos oferece estruturas para o dia, pontos de referência, pontos de parada, pontos para o olhar de relance e para a contemplação, pontos de engajamento e oportunidades de desengajamento. Os infinitos fluxos de representação da mídia são interrompidos por nossa participação neles. Fragmentados pela atenção e pela desatenção. Nossa entrada no espaço midiático é, ao mesmo tempo, uma transição do cotidiano para o limiar e uma apropriação do limiar pelo cotidiano. A mídia é do cotidiano e ao mesmo tempo é uma alternativa a ele (SILVERSTONE, 2005, p.25).

Na comunicação de massa o que importa não é a quantidade de indivíduos que recebe os produtos, mas o fato de estarem disponíveis para uma grande pluralidade de destinatários (THOMPSON, 2008, p.30).

O termo "massa" ainda sugere que os destinatários dos produtos da mídia são passivos e indiferenciados indivíduos, ideia essa associada a algumas das primeiras críticas que pressupunham que o desenvolvimento da comunicação de massa criava uma cultura homogênea, que prende a atenção sem ocupar as faculdades críticas e proporciona gratificação imediata sem questionamentos de tal (THOMPSON, 2008).

O estudo da mídia é importante "como algo que contribui para nossa variável capacidade de compreender o mundo, de produzir e partilhar seus significados (SILVERSTONE, 2005, p.13). É importante estudá-la, uma vez que além de presente em nosso cotidiano, ela o reflete, pois se utiliza de seus elementos e acaba por defini-lo, uma vez que contribui para a formação de opiniões sobre o mundo que nos cerca.

Nesse sentido, faz-se necessário trabalhar estas imagens de maneira coerente no contexto escolar para que os estudantes se tornem conscientes e críticos em relação aos acontecimentos da sociedade transmitidos cotidianamente e principalmente, sobre a influência de imagens publicitárias que incentivam o consumo exacerbado, e que como consequência, ocasiona gradativos problemas ao meio ambiente. Para entender como essa relação opera em nossa vida cotidiana, é importante fazer uma pausa para pensar o papel das imagens e sua influência persuasiva. Por isso mesmo, vamos partir de uma experiência com docentes da rede pública e discutir as principais contribuições da pesquisa com imagens de anúncios publicitários e a possibilidade de se trabalhar com a temática ambiental de acordo à análise crítica realizada pelos próprios professores.

\section{MÉTODO}

A utilização de imagens foi planejada e roteirizada de forma a contextualizar elementos presentes no cotidiano dos professores e chamar atenção para a possibilidade da utilização de imagens de diferentes fontes para estimular a criticidade dos indivíduos e principalmente trabalhar aspectos relacionados com o consumo.

O trabalho foi realizado com um grupo de 23 professores da rede pública como parte de uma oficina ministrada no munícipio de São Gabriel- RS, sendo esses professores de diferentes disciplinas. Foram realizadas duas atividades:

Primeira atividade: os professores organizaram-se em duplas ou trios e receberam livros didáticos e escolheram anúncios publicitários previamente selecionados por nós. Essas imagens eram publicidades de produtos de beleza, bebidas, alimentos naturais e outras que se relacionavam com o meio ambiente. Solicitamos que escolhessem uma imagem do livro didático e a comparassem com a do anúncio publicitário, como podemos observar as imagens da figura 1,2 e 3 .

Segunda atividade: os participantes receberam o texto Eu Etiqueta de Machado de Assis e foi solicitada a leitura e a elaboração de perguntas 


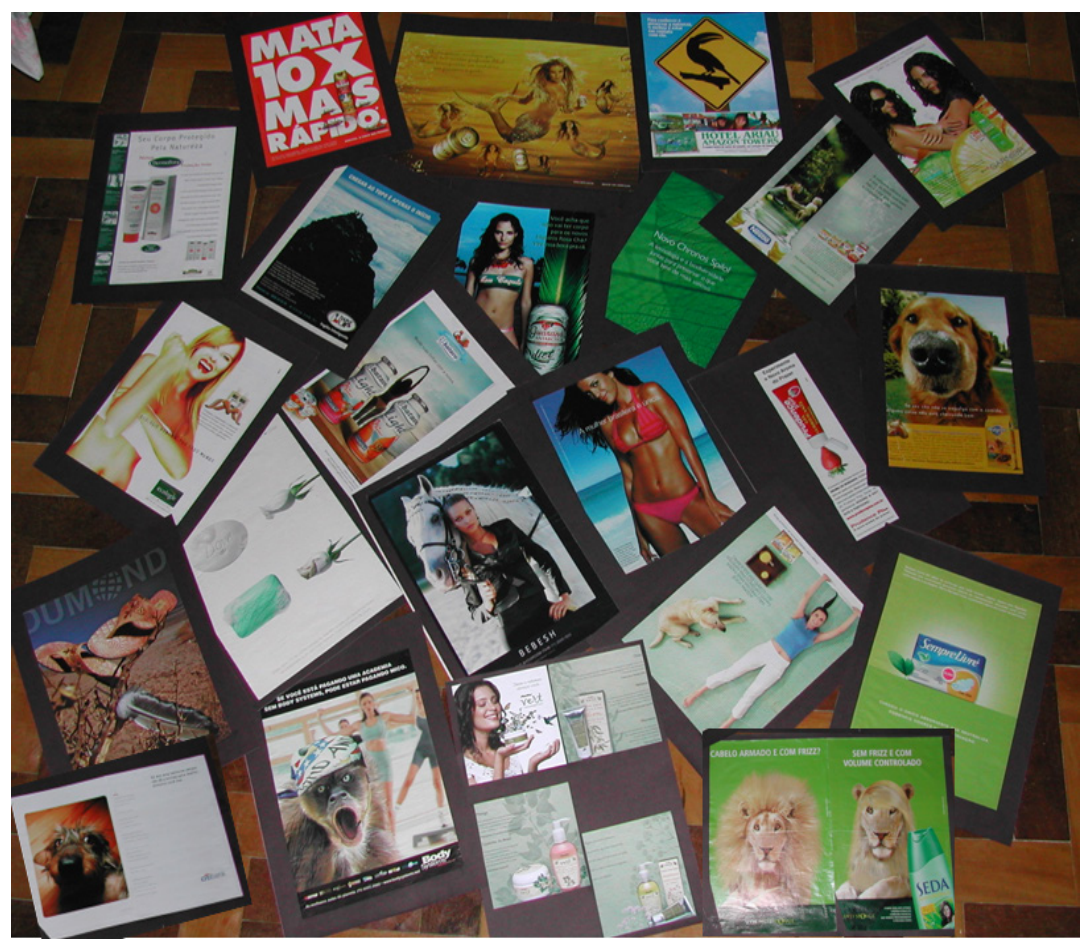

Figura 1. Imagens de anúncios publicitários.

Fotografia de Luciana Richter, 2012.

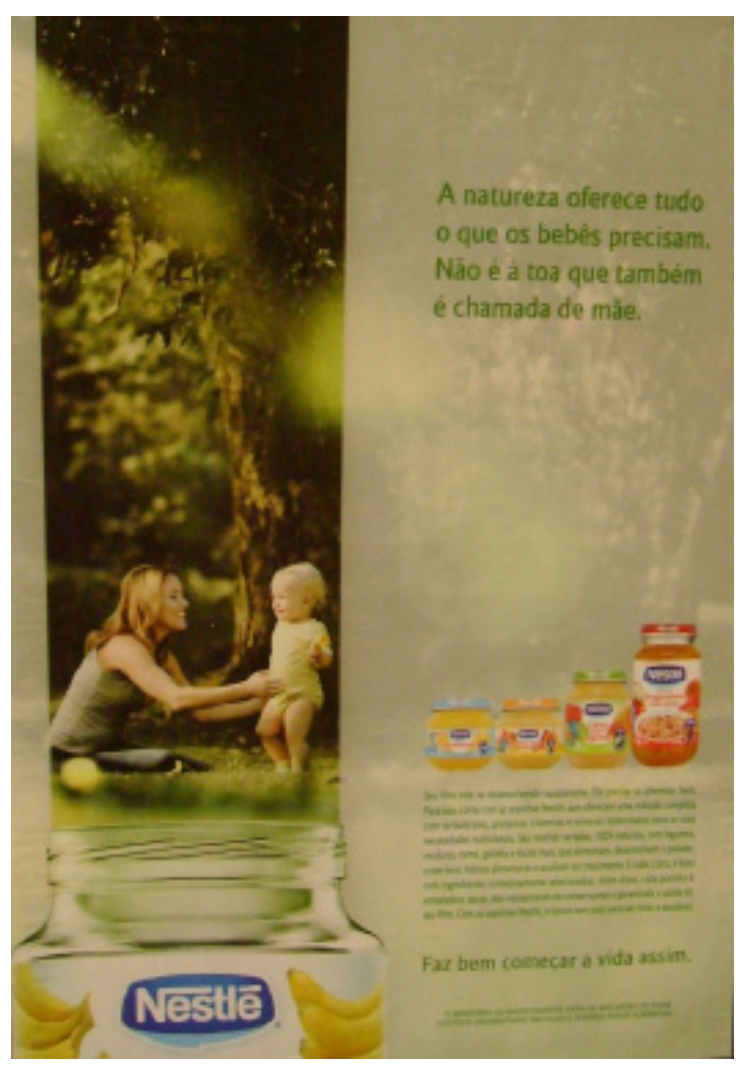

Figura 2. Detalhe de imagem de anúncio.

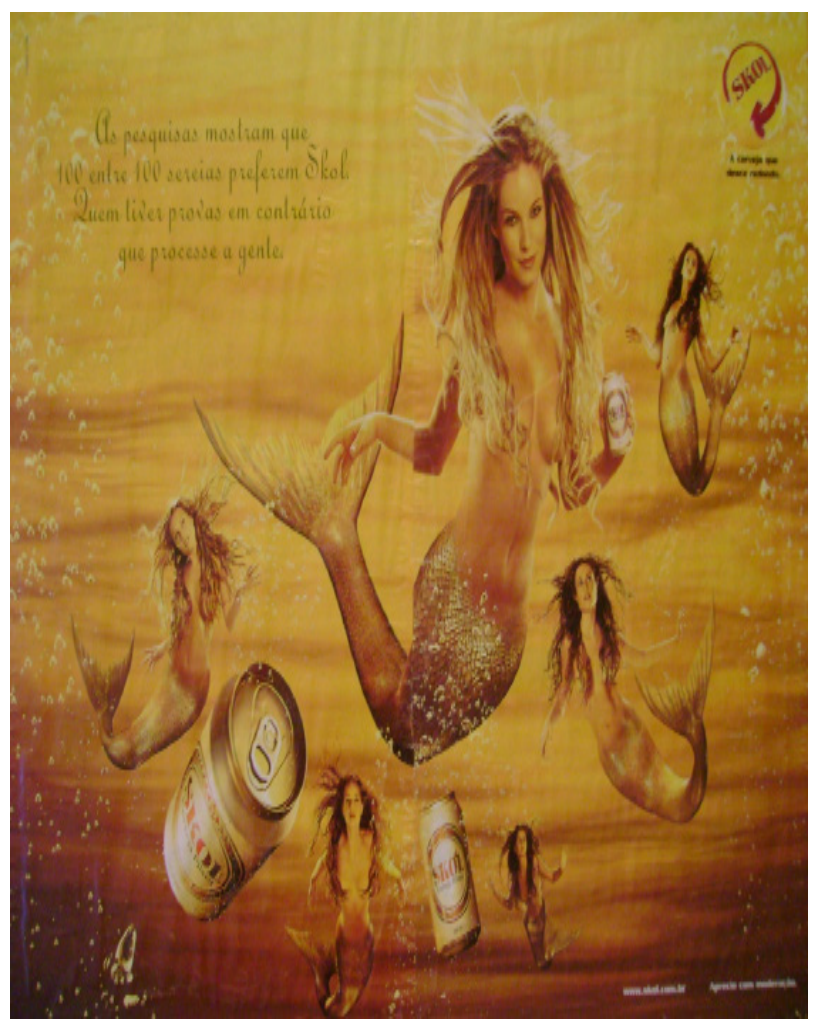

Figura 3. Detalhe de imagem de anúncio. 
relacionadas a temática abordada no texto, que de um modo geral, discute a relação pessoal que temos com o consumo de marcas, etiquetas e produtos industrializados. A exigência foi de que fossem feitas no mínimo duas perguntas por grupo. Posteriormente foram distribuídos balões e solicitado para que em cada balão colocassem uma pergunta e o enchessem. Já com todos de pé, ao som de uma música pedimos-lhes que brincassem de jogar os balões e foram orientados que a cada parada da música seria escolhida uma cor de balão, que já estava estipulada em uma ficha. Quem estivesse com tal cor, deveria estourar o balão e ler a pergunta ao grande grupo para que fosse discutida, a cada rodada foram lidas três perguntas. A dinâmica procurou introduzir os professores ao tema da oficina de modo lúdico e prazeroso, posto que muitos não se conheciam.

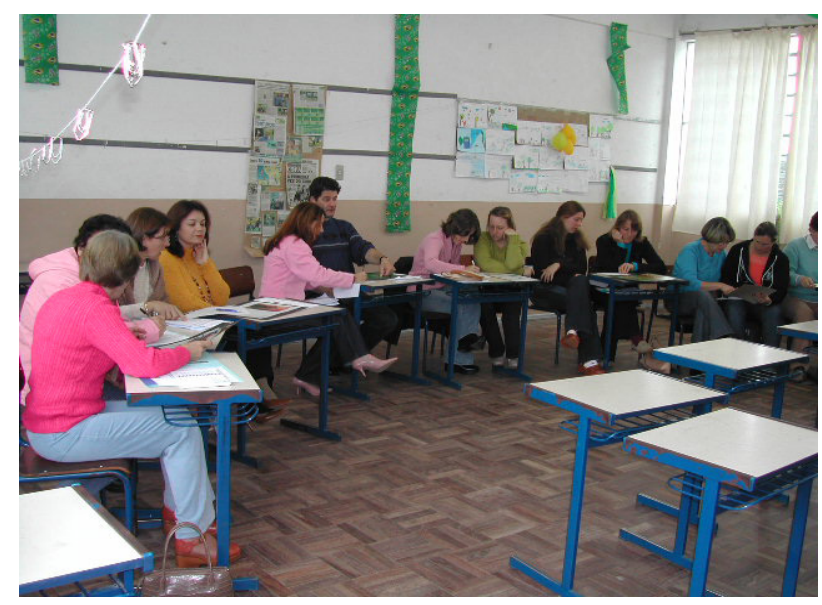

Figura 4. Professores trabalhando com as imagens. Fotografia de Luciana Richter, 2012.

Expostas as principais atividades trabalhadas durante a oficina com os docentes, no que segue, gostaríamos de apresentar alguns resultados e as discussões provocadas durante esta pesquisa.

\section{RESULTADOS E DISCUSSÃO}

As duas atividades transcorreram com a formação de cinco trios e quatro duplas, sendo as mesmas formadas por professores de diferentes áreas. Os professores relataram que foram ficando mais a vontade para falar ao transcorrer das atividades, o que enriqueceu as discussões. Para nortear a primeira atividade, após a escolha dos anúncios publicitários, os livros didáticos foram distribuídos de acordo com a formação dos professores (licenciados em Ciências Biológicas, Matemática, Geografia, História e Português) para que os mesmos se deparassem com imagens familiares das suas áreas.

$\mathrm{Na}$ exposição oral, os grupos compararam as imagens dos anúncios publicitários estabelecendo semelhanças e diferenças. Nessa atividade, os participantes produziram analogias relacionando a marca do produto com a legenda da imagem do livro didático, o texto que remetia a imagem ao texto que caracterizava o produto e expuseram que a imagem publicitária é mais rica em cor e que os detalhes que deseja ressaltar são mais evidentes dos que o das imagens do livro didático.

Entretanto, como foi apenas uma experiência comparando as imagens publicitárias com as de livros didáticos, embora os resultados pareçam simplistas, demonstram a potencialidade em se trabalhar com imagens provenientes de diversas fontes, pois mesmo que elas tenham sido elaboradas com propósitos diferentes, ambas possuem potencial pedagógico.

Num primeiro momento, os educadores reconheceram as possibilidades das imagens como auxiliares da comunicação pedagógica, recorrendo a elas para transmitir aos alunos determinados conteúdos temáticos, como forma de motivá-los na aprendizagem, ao menos experimentando o poder de captar a atenção que as imagens possuem e de ajudar os alunos na memorização (CALADO,1994). Isso fica evidente nas seguintes narrativas:

"Nunca tinha me dado conta de como uma imagem pode ter mais informação que um texto."

"As imagens publicitárias também podem ser usadas para ensinar, apenas é necessário que o professor saiba conduzir seu uso."

Para utilizar imagens como auxiliar didático, os docentes necessitam dominar a sua gramaticalidade, senão para escreverem imagens, ao menos para escolher as que dirão aquilo que eles desejam que seja dito (CALADO, 1994). Para a maioria das pessoas, o texto escrito ainda é o referencial mais importante e que legitima a construção do conhecimento científico, enquanto que a linguagem visual é usada para "adornar" textos ou como evidencia de algo. Não se pensa e pouco se usa a imagem como objeto do conhecimento, como uma linguagem com construções próprias e cuja leitura também exige um processo de aprendizado.

Na maioria das vezes, esse processo se dá de modo espontâneo: desde pequenos, estamos de alguma forma familiarizados com imagens, sejam 
elas dos álbuns de fotografias familiares, das figurinhas que se colecionavam, das revistas e jornais que se liam, dos outdoors e anúncios publicitários do meio urbano, também da televisão e do cinema. Atualmente, convivemos estreitamente com as imagens virtuais que nos são acessíveis através do uso da internet e que agora, carregamo-las por todas as partes nos celulares, Ipods, Ipads, Iphone e respectivos. Ou seja, não somos analfabetos visuais, usamos as imagens para nos comunicarmos mais e algumas vezes essas substituem o próprio texto, no entanto, quando as pensamos como um recurso pedagógico iniciam-se os problemas e as dúvidas recorrentes de como proceder.

A segunda atividade foi um momento muito rico de trocas, onde foi utilizado o texto Eu Etiqueta de Machado de Assis para discutir e problematizar a relação de nosso olhar consumidor com os produtos que nos são ofertados.

Após as leituras, os pequenos grupos começaram a elaborar perguntas relacionadas à temática abordada pelo texto e as colocaram dentro dos balões. Ao som da música os professores começaram a brincar de jogar os balões e a cada parada da mesma, uma cor de balão era escolhida. Quem tinha tal cor, estourou o balão e leu a pergunta ao grande grupo para discussão.

A diversidade de perguntas foi muito grande, mas as respostas e as principais discussões giraram em torno de nossa relação como consumidores e a escolha de produtos.

Esses são alguns exemplos de perguntas:

Por que compramos sempre o mais caro, embora haja um similar?

Por que as propagandas nos levam a pensar em determinado produto na hora da escolha?

Por que existem alguns produtos que são conhecidos pela marca? (Como exemplo o Omo, ao invés de sabão em pó)

Será que o produto mais caro é realmente melhor?

Se um produto que você já conhece estivesse em promoção e outro que fosse mais caro e você não conhece estivesse pelo mesmo preço, qual você levaria pra casa?

Você compraria roupas sem etiqueta?
O que a etiqueta muda em nosso comportamento?

Qual é a nossa etiqueta ao nos rendermos ao apelo dos rótulos?

Chegamos a um consenso de que os rótulos dos produtos, além de chamar a atenção dos indivíduos, influenciam na escolha dos mesmos por ser esteticamente atrativos ao nosso olhar (variedade de cores, formas e a limpeza na composição visual). Além disso, foram levantadas questões como a relação entre a qualidade do produto e seu rótulo, sendo que um participante indagou de tal forma:

Se nem se preocuparam com o rótulo, imagina como é que produziram o que estão vendendo. A embalagem é o inverso de nós, pois é como se fosse uma alma externa que reflete o que vai estar dentro.

No mundo globalizado e capitalista, é cada vez mais recorrente o uso da publicidade para promover e vender produtos. De acordo com Trajano (2012, p.02), a sociedade capitalista tem como base o consumo de objetos e materiais sejam qual for a sua natureza: "para que o consumo se realize, é necessário que haja uma promoção que seja eficaz, do contrário o objetivo não será alcançado".

A discussão de cada uma das perguntas acabou levando os participantes a questionarem no fim dessa atividade sobre quais seriam as consequências do consumismo estimulado tanto pelos anúncios publicitários quanto pela mídia de forma geral.

Surgiram questões como:

Qual o impacto ambiental de sempre se querer estar na moda? Qual a destinação do que já se possui?

Quanto recurso natural é necessário para manter o nível de consumo que os anúncios publicitários almejam?

Por que não se aborda impacto ambiental através de imagens de anúncios em sala de aula?

Os professores chegaram à conclusão a partir da discussão dessas questões de que não é fácil ter ideias sozinhos de como problematizar assuntos em sala de aula. A maioria relatou nunca ter pensado na relação do consumismo com a questão ambiental e apontou a temática como 
algo promissor a ser discutido no ambiente escolar. Convém ressaltar que a publicidade usa dois discursos que juntos cumprem um importante papel de persuasão: o discurso verbal e o visual. Quando pensamos em visual, remetemo-nos a uma série de imagens cuja natureza e difusão é bastante diversa. Nesse caso, a imagem geralmente é mais do que aquilo que representa porque possui um discurso polissêmico e uma cadeia de significados, cabendo a que a lê, um modo distinto de significá-la (RIAL, 1995). Uma pintura, um desenho, inclusive uma fotografia podem dar margem a interpretações e significados distintos, dependendo da intenção das mesmas e do contexto no qual está inserido. No entanto, quando a imagem é usada para fins publicitários, ela é apresentada de modo a produzir uma leitura dirigida e que sirva para comunicar ao consumidor uma ideia ou um conceito muito específico do produto "a imagem publicitária não teria um oculto, não estaria no lugar de, ela é" (RIAL, 1995, p.121).

\section{CONSIDERAÇÕES FINAIS}

O uso articulado e propositivo das imagens dos anúncios publicitários nos leva a refletir sobre o papel preponderante da imagem no mundo contemporâneo e mais especificamente, na nossa vida cotidiana (BERGER, 1999). Como comentado neste artigo, os avanços tecnológicos, o uso indiscriminado de aparatos digitais e da internet, faz com que a velocidade de percepção das imagens seja alterada. Vemos centenas de ícones, cores e formas, identificamos conteúdos, conceitos e idéias, internalizamos desejos e necessidades consumistas, mediamos nossa relação com as pessoas através do uso de imagens, sejam elas fotográficas, pictóricas, mas especialmente, publicitárias.

O espaço educativo, como um lugar de aprendizado e construção do conhecimento por excelência, muitas vezes também reproduz o status quo e alguns estereótipos sociais (ALVES, 2001). No entanto, ainda é um espaço que permite momentos de diálogos críticos, de reflexão sobre nossa cultura e a construção de olhares diferenciados sobre assuntos polêmicos e do cotidiano. $\mathrm{O}$ uso de imagens na educação possibilita trazer para o espaço da sala de aula, novas formas de olhar um mesmo objeto de estudo ou temas emergentes na sociedade, sendo uma maneira distinta de aprender e compreender.

O uso de imagens como recursos pedagógicos gera insegurança e é visto por alguns como algo difícil quando se pensa em utilizá-las nos planos de aula. Isso se deve a dois aspectos iniciais: a. em muitos casos, não percebem a imagem como provocador de discussões, como objeto de aprendizado; $b$. na pressa e na correria de preparar dezenas de aulas, de avançar no conteúdo que se exige, as imagens acabam sendo pouco influentes no programa de ensino dos docentes.

Outras vezes, o próprio caráter polissêmico da imagem provoca dúvidas sobre como "deve" ser lida e usada na sala de aula. Nesse sentido, podemos argumentar duas necessidades em se tratando do uso da imagem em sala de aula: a. da formação e preparação contínua dos docentes sobre as múltiplas possibilidades da imagem e seu potencial pedagógico; $b$. aprender a ver e a priorizar as imagens como parte do processo de preparação dos conteúdos programáticos, como algo que pode ser tão importante quanto à escrita e a leitura.

De modo mais específico, podemos concluir que é importante que o ensino de Ciências permita ao estudante associar e relacionar os conteúdos escolares com aplicações em sua vida, sendo o professor um mediador da aprendizagem. Se o professor aprende a ver e a pensar as imagens de anúncios publicitários de forma crítica, também ensina a vê-las e questioná-las criticamente com seus estudantes.

\section{REFERÊNCIAS BIBLIOGRÁFICAS}

ALVES, M. A. Filmes na escola: uma abordagem sobre o uso de audiovisuais (vídeo, cinema e programas de TV) nas aulas de Sociologia do Ensino Médio. Dissertação de Mestrado. Campinas, SP: Unicamp, 154 pgs., 2001.

BERGER, J. Modos de ver; tradução de Lúcia Olinto. - Rio de Janeiro: Rocco, 1999.

\section{CALADO, I. A Utilização Educativa das Ima-} gens - Coleção Mundo de Saberes 8 .Portugal, Porto Editora, LDA, 1994.

GHILARDI, M. I. Mídia, Poder, Educação e Leitura. In: BARZOTTO, V. H. e GHILARDI, M. I (Orgs.). Mídia, Educação e Leitura. São Paulo: Associação de Leitura do Brasil, p.103-112, 1999.

KELLNER, D. Lendo Imagens Criticamente: Em Direção a Uma Pedagogia Pós Moderna. In: SILVA, T.T. da. (Org.). Alienígenas na sala de aula: uma 
introdução aos Estudos Culturais em Educação. 8. ed. Petrópolis, RJ :Vozes, 2009, p. 190-207, 2009.

LOPES, L. C. O Culto às Mídias: interpretação, cultura e contratos. São Carlos: EdUFSCar, 2004.

MUNIZ, E. Comunicação publicitária em tempos de globalização. Canoas: ULBRA, 2005.

RIAL, C.S. Por uma antropologia do visual contemporâneo. Horizontes Antropológicos, Porto Alegre, ano 1, n. 2, p. 119-128, jul./set., 1995.

ROCHA, C. F. O espaço escolar em revista. In: COSTA, M. V. (Org.). Estudos culturais em educação: mídia, arquitetura, brinquedo, biologia, literatura, cinema. 2. ed. Porto Alegre: Ed. Universidade/ UFRGS, p. 117-142. 2004.

SILVERSTONE, R. Por que Estudar a Mídia? São Paulo: Loyola, 2005.

THOMPSON, J B. PA Mídia e a Modernidade: Uma teoria Social da Mídia - trad. BRANDÃO, W. O.10. ed. Petrópolis, RJ :Vozes, 2008.

TRAJANO, I.S.N. A imagem e sua função semiótica em discursos multimodais. Anais do SIELP. Volume 2, Número 1, pp.01-10. Uberlândia: EDUFU, 2012. 